\title{
A COVID-19 E A POPULAÇAO NEGRA
}

\author{
Míriam Cristina Soares Lino Teodoro
}

Escola Estadual Coronel José Teófilo Carneiro.

E-mail: mairimanistirc@yahoo.com.br

Dulce Pereira dos Santos

Universidade Estadual de Montes Claros - Unimontes.

E-mail: dulce.santos@unimontes.br

\begin{abstract}
RESUMO
Este trabalho tem como objetivo apresentar e discutir dados divulgados sobre a COVID 19 e a população negra, bem como análises que foram sendo feitas através de noticiários e leituras diversas a respeito do assunto. Embasamos também nas conversas/palestras e aulas realizadas no Grupo de Estudo Ensino de Geografia e Relações Étnico Raciais onde o debate sobre a condição da população negra sempre foi discutida com muita responsabilidade. Diversos tópicos sobre a condição deste povo foram discutidos ressaltando a importância, a necessidade e a urgência de se falar sobre o tema. Durante a pesquisa podemos perceber a falta de estrutura em que vive uma grande parcela da população negra no Brasil e no mundo e as consequências quanto ao enfrentamento de diversos problemas sociais, principalmente no que tange ao Covid19, que já matou milhões de pessoas pelo mundo e que mais de $50 \%$ desses mortos são pessoas negras privadas muitas vezes de seus direitos fundamentais.
\end{abstract}

Palavras-chave: População Negra. Covid 19. Racismo.

\section{INTRODUÇÃO}

O homem como sujeito de direitos deve ser tratado de forma igual. É sabido, entretanto, que os direitos humanos não são universais. A condição social, exclui e por vezes, mata grande parcela da população seja por falta de acesso a serviços básicos como saúde ou pela violência. A população de baixa renda que em sua maioria são afrodescendentes e pardos são intimidados pelo sistema nas formas: moral, sexual, social, psicológica, física, material e verbal. Fazendo que de certa forma aconteça um genocídio desta população.

Djamila Ribeiro em seu livro "Combata a violência racial", nos alerta sobre o quantitativo de pessoas negras que são mortas no Brasil. Os casos de violência contra a população negra são assustadores e crescentes.

No momento atual mais um descaso com esta população se faz visível na forma da não assistência quanto aos cuidados e enfrentamento da Covid-19 se mostrando ineficiente os tratamentos e cuidados para com a população pobre e negra da sociedade. 


\section{DESENVOLVIMENTO}

A Covid-19 é uma doença causada pelo vírus SARS-CoV-2 e que assola milhões pelo mundo e que ainda não se sabe ao certo de onde veio e como surgiu. É uma doença altamente contagiosa e pode ser letal, o que exige das pessoas novos hábitos de comportamento e higiene, podendo ser sua disseminação reduzida se seguidas às normas sugeridas pela Organização Mundial da Saúde - OMS.

Em 2020, milhares de pessoas foram privadas de sua liberdade plena na tentativa de conter a transmissão da Covid-19, devido ao risco letal da doença. Alguns grupos são tidos como grupos de risco, dentre os quais podemos citar: idosos, pessoas com doenças crônicas, dentre outros.

Em meio a tudo isso, mais uma vez percebemos que no Brasil a condição social é um fator que mata. E neste cenário atual recebemos notícias e dados alarmantes que mostram o número assustador de mortes por esta enfermidade. Os fatores são os mais diversos: moradias sem infraestrutura, falta de água, ineficiência do sistema de saúde, exposição. Todos os dias os noticiários de televisão nos mostram a triste realidade vivida por milhares de pessoas.

A pobreza no Brasil tem raça/cor, sexo e etnia. Esta afirmação, interpretada por alguns como esquizofrênica, está pautada em números tão cruéis quanto seu reflexo nos corpos e nas mentes de negros e negras, índios e índias (LOPES, 2004, p.12).

Postos de trabalhos fechados, diaristas sendo expostas ao risco, empresários se aproveitando da situação e lesando funcionários, crimes sendo cometidos, desvios dos recursos destinados ao tratamento e prevenção da doença, e auxílios governamentais não chegando a muitos que deles necessitam. Ora com tudo isso em todo o mundo, onde estão os pobres e pretos?

Estão nas casas de seus patrões, nas obras (construções civis), dirigindo os transportes públicos, e com isso se expondo a riscos e levando este risco para suas famílias. Neste cenário triste e desolador vimos que até os países de primeiro mundo estão sofrendo. Situações devastadoras para a economia e perda de milhares de vidas humanas. Ressaltamos que a economia ao longo do tempo com paciência e trabalho se recupera, mas as vidas perdidas não.

Países de primeiro mundo estão empenhados a salvar vidas e consequentemente investem firmes em políticas públicas quanto a construção de hospitais em tempo recorde para prestarem atendimento emergencial. A tecnologia é aliada em alguns 
países com a utilização de drones auxiliando na entrega de comida, remédio e até mesmo ordenando que pessoas fiquem em casa quando observados casos de aglomerações e nem assim conseguem frear totalmente as perdas. Mas, infelizmente, em países periféricos a situação é ainda pior e falta até mesmo atendimento, medicamentos e profissionais para atender a grande massa populacional.

Os governantes são nossos representantes e deveriam zelar pela saúde da população. Muitos defendem o fim do isolamento social ou pelo menos parcial, a economia precisa girar, mas se não tiver mão de obra suficiente? No caso do Brasil a impressão que temos é que os governantes pouco se importam, se mostrando irresponsáveis quando saem às ruas sem proteção e incentivam a população a fazer o mesmo.

Uma parte da população brasileira mora em lugares insalubres, vivem em situação precária e não têm condições de se equiparem com os insumos necessários a sua proteção, o vírus pode ser fatal e se instala em qualquer ambiente, mas é evidente que nestas condições os maiores índices de infectados abrange a população de baixa renda que em sua maioria no Brasil são os negros.

Ao observarmos a espacialização do Covid-19 percebemos que o vírus se espalha sem distinção de países desenvolvidos ou países subdesenvolvidos. O que observamos é o grande número de contaminação e óbitos que no mês de novembro/2020 se mostra em alta em diversos países, até mesmo onde já se pensava que estava estabilizado conforme mostram os Gráficos 01 e 02.

Gráfico 01 - Recorde de casos diários de Covid 19.

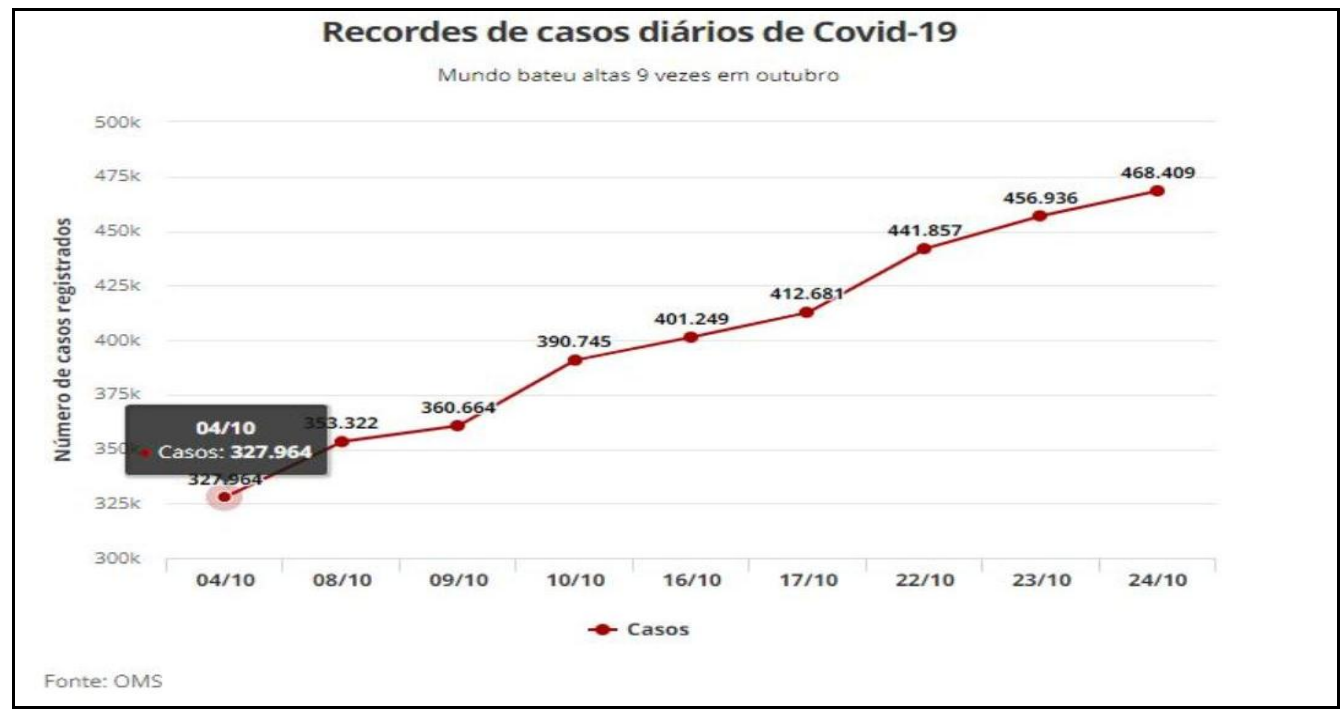


Gráfico 02 - Países com mais casos de Covid-19 em outubro/2020

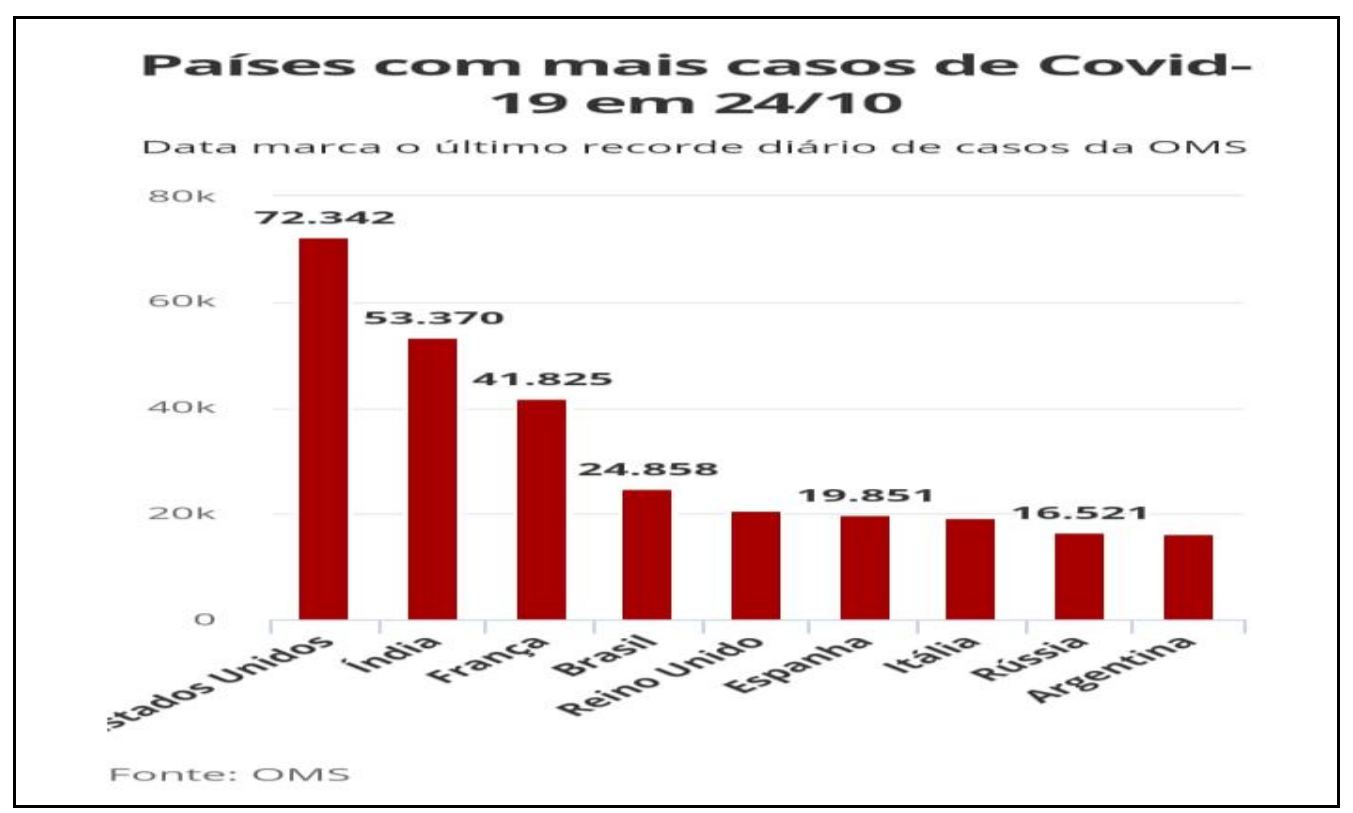

Em meio a tanto sofrimento percebemos a luta de milhares de pessoas determinadas na tarefa de ajudar a salvar vidas. Mas, e a vida pós pandemia como vai ficar? Não podemos prever, mas sem dúvidas podemos nos arriscar em dizer que para muitos se acentuarão as dificuldades para se alimentar e sobreviver, uma vez que muitos não terão mais seus empregos como os postos de trabalho fechados.

Para diminuir os impactos causados pela Covid-19 serão necessárias políticas públicas destinadas a esses grupos e tentar minimizar as desigualdades sociais.

\begin{abstract}
Sabemos que um dos primeiros passos para minimizar as vulnerabilidades é identificar os direitos não efetivados tanto do ponto de vista individual quanto do coletivo e, em seguida, elaborar estratégias de promoção. A perspectiva universalista do quadro de Direitos Humanos oferece uma referência generalizável sob a qual se pode examinar qualquer contexto social ou estrutura de programa, avaliando o quanto esses afastam (ou aproximam) as pessoas dos mais altos e desejáveis padrões de qualidade de vida (LOPES, 2004, p.14)
\end{abstract}

Dando ênfase ao tema, no dia 30/04/2020 vimos uma figura do cenário jornalístico perder a luta contra o Covid-19, estamos nos referindo a um jornalista branco de 88 anos formado em filosofia e direito. Fato este noticiado em várias emissoras de televisão. E quanto aos não famosos? São tantos! São aqueles que seus familiares imploraram por uma vaga na UTI, aqueles que ficaram nos corredores das unidades de saúde, aqueles que nem sequer tiveram atendimento, aqueles que nem chegaram a um hospital ou unidade de saúde. E ainda são aqueles que vivem em 
comunidades amontoados em pequenas moradias e que não podem se dar ao luxo de um isolamento.

Como dito anteriormente o isolamento social se torna impossível para uma parcela da sociedade devido a fatores também mencionados anteriormente, mas o que queremos salientar neste momento é a dificuldade de se manter no isolamento grande parte dos idosos, isto em se referindo aos idosos que são grupo de risco e não estão em seus apartamentos luxuosos, mas àqueles que sentem a necessidade de estar em meio às pessoas e se interagir porque para eles é a única forma de socialização e se não o fizerem podem de fato adoecer de tristeza, então preferem o risco de serem infectados com o Covid-19 a adoecerem sozinhos em casa, mas há também aqueles não o consegue fazer pelo simples fato de não conseguirem ficar em casa.

Muitas campanhas de apoio e solidariedade estão sendo destinadas aos idosos para minimizar os impactos do isolamento, mas é preciso salientar que estas atitudes devem permanecer além pandemia, pois o cenário em que vivem muitos idosos é de total descaso e esquecimento por parte dos familiares. Para além do problema com os idosos, devemos também citar o aumento de casos de violência contra a mulher.

Em uma sociedade de extremas desigualdades não seria diferente quanto ao enfrentamento da Covid-19. Uma doença que assola o mundo sem distinção, seja desenvolvido ou subdesenvolvido. O que sabemos é que grande parte da sociedade que sofre com esta doença é sem dúvida a população de baixa renda, onde encontramos um elevado percentual de negros, fruto de uma estrutura que não acolhe como deveria e nega os direitos na forma de racismo estrutural.

No Brasil, há muito tempo vivemos estes desajustes, frutos da escravidão que coloca os negros numa posição de inferioridade. Mesmo tendo um sistema de saúde pública, todos os dias milhares de vidas são ceifadas devido à falta de acesso a cuidados básicos necessários ao enfrentamento a covid-19. Em meio a tudo isso devemos também relacionar a saúde mental desta população.

\footnotetext{
Assim, sob uma análise para além da situação epidemiológica, nota-se que o país apresenta uma desigualdade social e étnico-racial marcante quanto às condições de habitação, renda e estrutura demográfica. Isto coloca em vigilância a necessidade premente de identificar espaços e populações de maior vulnerabilidade à COVID-19, com vista à otimização do controle da dispersão e prevenção de forma grave da doença. (MATOS et al apud KIM et $a l, 2020, \mathrm{p} .1351)$.
}

Podemos visualizar o grau de infecção da Covid-19 de uma forma simples. Onde 
mora a população negra do Brasil? Em sua maioria em bairros periféricos, muitas vezes desprovidos até mesmo de saneamento básico. Nos postos de saúde e hospitais públicos a população negra são a maioria, inclusive no número de óbitos devido a Covid-19. Isso tudo fruto de uma segregação racial promovida pela escravização ocorrida no Brasil no período colonial e apresenta resquícios na sociedade atual.

Os fatores mencionados por si só diminuem as expectativas de vida da população negra conforme relata o médico sanitarista e professor de saúde pública da USP Gonzalo Vecina Neto "Os pobres são atingidos de forma "muito violenta" em relação aos "remediados e ricos" e ainda conforme Gragnani (2020, p. 1) "De acordo com estudos realizados pelo Núcleo de Operações e Inteligência em saúde da PUC-Rio, pretos e pardos realmente morrem mais por Covid-19 no Brasil, isto baseados em variáveis como demografia e condição socioeconômica".

Segundo Matos et al. (2020), a população negra devido ao preconceito ou preferências acaba sendo negligenciada no atendimento e no acesso aos serviços da pandemia, cria-se uma hierarquia no atendimento que envolve tanto os cuidados quanto nos resultados de saúde.

Em estudos realizados pelo Núcleo de operações e Inteligência em saúde da PUC- Rio até meados de maio foram analisados cerca de 30 mil casos de Covid-19 disponibilizados pelo Ministério da saúde. De acordo com este estudo, mais de 50\% dos casos de Covid-19 do período são de pretos e pardos que morreram acometidos pela doença, sendo que o número de óbitos entre a população branca não chegou a $40 \%$. Podemos perceber estas disparidades conforme o gráfico 03.

Gráfico 03 - Percentual de óbitos de internados.

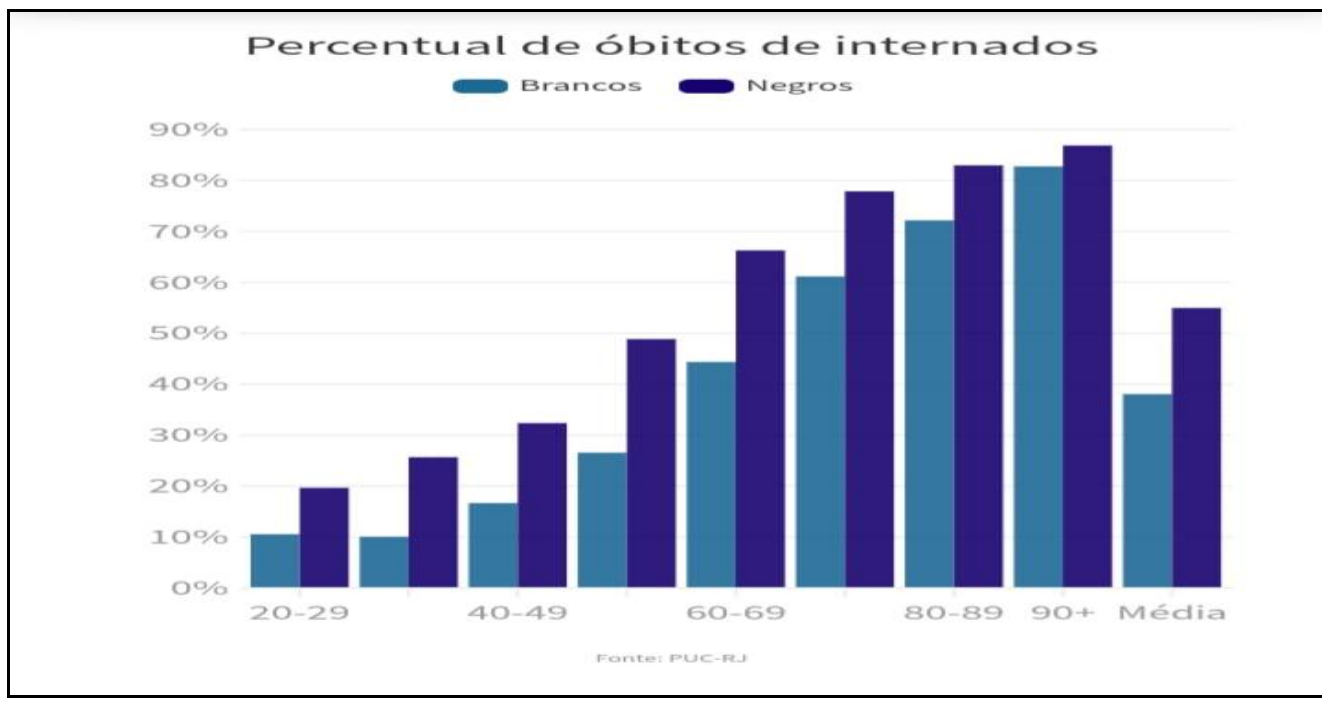


Estas disparidades não acontecem somente no Brasil, podemos visualizar este fenômeno em diversos países, o que reforça a ideia do racismo estrutural na história mundial colonial e contemporânea. O Brasil é um país que prega a igualdade, entretanto a equidade continua sendo uma palavra desconhecida pela sociedade brasileira, visto que a média de vida da população negra se mostra bem inferior à média de vida de não negros.

\section{CONSIDERAÇÕES FINAIS}

Podemos dizer com este trabalho que as condições socioeconômicas, a falta de políticas públicas e o racismo estrutural são condições relevantes para o alto índice de mortalidade entre a população negra causada pela covid-19.

Essa população teve e tem que exercer normalmente suas funções na sua atividade laboral porque é dessa atividade que vem a renda para a sobrevivência de suas famílias, ficando assim expostas ao risco no trabalho, no transporte, nas estações de trem e ônibus e também sem a assistência médico-hospitalar adequados. Ressaltamos que condições sanitárias, isolamento social e o distanciamento são primordiais para diminuir o índice de contaminação sendo que esta parcela da sociedade é a mais exposta a tudo isso.

Contudo, diante do dilema vivido por toda uma sociedade, são evidentes as transformações ocorridas em todo cenário mundial. Os impactos nas áreas de saúde, economia, esporte, lazer e turismo são os mais diversos desde a redução de capital até o desemprego que assolou milhares de trabalhadores.

A sociedade precisou se adequar a novos hábitos para minimizarem-se os impactos causados pela Covid-19, o isolamento social e o distanciamento é necessário, mas infelizmente algumas pessoas seja pela natureza do trabalho (Trabalhadores da saúde, motoboys, frentistas, trabalhadores de supermercados, farmácias e de limpeza) não podem parar e além desses, existem os trabalhadores negros e pobres, os informais que vivenciam um dilema ou ficam em casa ou vão em busca de algum trabalho para garantir a sobrevivência.

A humanidade nos últimos meses está enfrentando um grande desafio, onde todos os povos deveriam se unir com um único objetivo, que é o de salvar vidas indiferentemente de sua classe social ou cor da pele. Sendo assim, uma solução eficaz contra a Covid-19 é a descoberta de uma vacina que está em estudo em diversos países, 
que está chegue com uma eficácia consistente, de boa qualidade, gratuita, para todas as idades, raças e etnias, sem efeitos colaterais e que seja capaz de ajudar a acabar com essa pandemia tão catastrófica.

\section{REFERÊNCIAS}

BRASIL. Fundação Nacional de Saúde. Saúde da população negra no Brasil: contribuições para a promoção da eqüidade / Fundação Nacional de Saúde. - Brasília: Funasa, 2005.

GRAGNANI, Juliana. Porque o coronavírus mata mais pessoas negras e pobres no Brasil e no mundo. Disponível m: https://www.bbc.com/portuguese/brasil. Acessado em: $27 / 11 / 2020$

CRUZ, I. C. F. D et al. Brasil. Fundação Nacional de Saúde. Saúde da população negra no Brasil: contribuições para a promoção da eqüidade / Fundação Nacional de Saúde. - Brasília: Funasa, 2005.

MATOS, A. P. V. et al. Impactos da pandemia gerados pelo novo coronavírus em populações negligenciadas: uma revisão sistemática. In: Guilherme Antônio Lopes de Oliveira; Liliane Pereira de Souza. (Org.). A sociedade em tempos de covid-19. Mato Grosso do Sul: Editora Inovar, 2020, v. 1, p. 1350-1357.

SANTOS, B. S. A gramática do tempo: para uma nova cultura política. São Paulo: Cortez, 2006.

\begin{tabular}{|c|c|c|c|}
\hline (9) & eISSN 2594-9810 & Revista Ciranda (DEPE-UNIMONTES) & DOI: $\underline{10.46551 / 259498102021040}$ \\
\hline 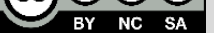 & -Recebido em: 14/ & ./2021 Aceito em: 22/jul./2021 & cado em: 08/set./2021 \\
\hline
\end{tabular}

